\title{
Identifying the Gaps of Health Communication Research: A Systematic Review
}

\author{
Nidhi Sharma \\ Ph.D. Research Scholar, University Institute of Media Studies, \\ Chandigarh University, Gharuan, Mohali, Punjab \\ Dr. Fakira Mohan Nahak \\ Associate Professor, University Institute of Media \\ Studies, Chandigarh University, Gharuan, Mohali, \\ Punjab \\ Dr. Rubal Kanozia \\ Asst. Professor, Deptt. of Mass Communication \& Media Studies, \\ Central University of Punjab, Bathinda, Punjab
}

\begin{abstract}
The Indian scripture Upanishad says, "Shariramadyam Khalu Dharma Saadhanam", means the physical body is the base and medium for all good actions. But due to the massive industrialization, over dependency on technology, sedentary lifestyles, worst food habits and work-life imbalance the physical body of human being is losing its vigor. As a result the deteriorating health has become a major concern for most of the developed, under developed and developing countries. All the medical sciences professional, doctors and health professionals are talking about the drugs-based solutions, but health communicators talk about preventive measures and precautionary approaches. The ever- changing sociocultural dynamics is directly or indirectly affect the health-related issues in these countries. Particularly in India, preventive health communication strategies remain ignored, when it comes to awareness and extension education. In such cases, media supported health communication strategies are highly recommendable to achieve the goal of healthy body and healthy mind. These health communication strategies could play a very important role in developing and underdeveloped countries, where people are not much aware of the diseases and their preventive measure. In this paper the researchers have tried to make a systematic literature review of 20 different research outcomes of health communication. And tried to present a very important and in-depth of past studies of health communication in India and Abroad. This systematic review has directly dealt with media and its role in health promotion, agenda setting for health, behavior theories etc. This study has helped the researchers to draw future line of action for the new researches in the field of Role of Media in health awareness \& Health Communication.
\end{abstract}

Keywords: Health Communication, Behavioral Change Communication, HBM, Social Cognitive Theory.

\section{Introduction}

Health Communication is an interdisciplinary, progressive and dynamic subject area of research, which is getting immense popularity because of its applicability and widely acceptance among health professionals and media communicators (Nishiuchi et al., 2016; Sanders, 2010). Due to its wider acceptance among health, social, communication and data scientist, it has received attention of the researcher of various diverged field to collaborate for an in-depth and inclusive research(Academy et al., 2018; Stacey et al., 2015). In this regard, various health communication models along with theories are emerged as key concepts are making this a trans-disciplinary area of research. Most of the health researchers are working on health belief model, agenda setting for health awareness, multilevel health education model, social learning theory, and social cognitive theory, the theory of planned behavior, the trans-theoretical model \& diffusion of innovation for theorizing the research. (Bullen \& Roberts, 2018; Ebina et al., 2010; Glanz \& Bishop, 2010; Hausenblas et al., 2001; Kozel et al., 2006; Nishiuchi et al., 2016; Scheirer et al., 2017).

Health Communication comprises two words health and communication, which means communicating the health values by using effective means of communication to generate 
masses(Nishiuchi et al., 2016; Stacey et al., 2015). Health Communication mainly initiates a positive dialogue between health professionals, health communicators and media professionals with one aim: making echo for health rights, health belief, health education and health awareness at ground level (Kozel et al., 2006; Scheirer et al., 2017; Starmann et al., 2018). Health Communication discipline mainly aim to pump up public health campaigns to initiate health favorable rhetoric. The key strategy of the health communication is to inform the masses about health issues, challenges and opportunities particularly focusing on two approaches, mass media \& interpersonal campaigning through health educators, health workers and NGO"s(Glanz\& Bishop, 2010; Llamas \& Mayhew, 2016).

The objective of health communication is to disseminate health information and knowledge among individuals as well as society by improving health literacy. Under the health communication strategies, firstly health message/idea is framed and the target audience is selected. The medium of message is decided according to audience and geographical situations. Generally researchers have adopted four approaches in HC strategies which include information, education, persuasive and prompting. NIH (National Health Institutes and Centre for Disease and Prevention) defined as "Health Communication encompasses the study and use of communication strategies to inform and influence individual and community decision that enhance health."(2011). Being a practitioner of health communication, a strategist raises health issues, health risk and health solutions with the help of experts. A health communication practitioner formulates community point of view, set public health agenda, advocates policies and programs among masses so the delivery of public health and health care services shall reach to the remotest area as well. (Academy Et Al., 2018; Mcbride, Birmingham, \& Kinney, 2015; Mertens, Távora, Nakano, \& Castilhos, 2017; Scheirer Et Al., 2017).

Theoretical Framework on Health Communication and Social Change

In this study, researchers have studied the research papers related to health communication, behavioral 
communication and health \& media. These research papers have been taken from various national and international journals of high repute. The researchers have critically evaluated the health communication, health \& media as a primary unit of study. This method is helpful in identifying the main characteristics of the particular subject and it allows one to explore the new areas, approaches and elements to strengthen the argument for research. In this study researchers have found the following topics which are directly associated with health communication and making it a trans- disciplinary area of research health and communication practitioners:

While exploring the above mentioned key concepts researchers have established an inter- disciplinary connection that will further strengthen the dialogue or rhetoric of health communication in India.

\section{Agenda setting for health awareness}

Agenda setting clearly defines that media sets an agenda before public, though this theory is established in connection to Mass media and political discourse, but the influential media is capable of setting social, cultural, environmental and health discourse among people(Harris et al., 2018; Kozel et al., 2006; Llamas \& Mayhew, 2016). This theory clearly state that media frame opinion on particular issues among masses (Llamas \& Mayhew, 2016). People who are under heavy media exposure are highly exposed to such preventive content related to health. In 1968, during the American election, Max Mac Combs and Donald Shaw developed agenda setting theory. However, with passage of time, this theory enters into the most of the

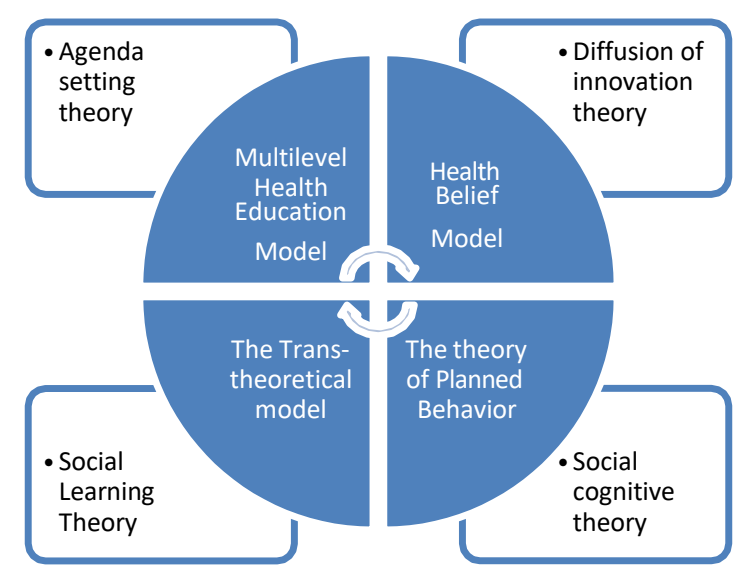


communicative approach(Bang, Chae, Lee, Yu, \& Kim, 2018; Kozel et al., 2006; Llamas \& Mayhew, 2016). According to Harris et al., noticed that personal beliefs, ideations, motivations opens up a new path way to analysis the effective use of media for the generation of health awareness at ground level (Harris et al., 2018).

\section{Multilevel Health Education Model}

This model explain that how social, economic and cultural aspects of the society framed the health behavior. Williams Olajide and Swierad

M. Ewelina (2019) state that multisensory multilevel health education model explain three important domain which includes art of innovativeness \& creativity. It also includes cultural tailoring and science based promotion of health belief among masses. In this model, scholar emphasized about the use of innovativeness, creativity and socio-cultural activity to create health awareness and belief during health campaigns (Williams \& Swierad, 2019). In this paper, researchers have analyzed thoroughly Multilevel Health Education Model that can be used in designing effective health intervention and campaigns.

Lane et.al (2009), in research article "There are several persuasive strategies for media health campaigns as anti-diseases campaigns for engaging masses for good health response system." This study is sustaining the view that communication strategies, communication channels and approaches can help in health care intervention. Heath Communication practitioners involves mass media institutions as one of the best tool to reach the masses, this will definitely help them to develop a direct connect and bridge the gap between them. (Williams \& Swierad, 2019).

\section{Social learning theory of human behavior}

Social learning theory about learning of social behavior in lieu of HC, Communicator cultivating the masses behavior, attitude as well as knowledge about health information. McBride et.al(2015) revealed that in cancer prevention, detection and treatment, health communication practitioners must evaluate these two factors while implementing any strategy: first one is effective communication including patient-provider communication and second one to change the lifestyle choices of the people they must include some motivational impact and behavior change 
strategies to yield (McBride et al., 2015). Even the (Three P) P-Positive Parenting Programme is a comprehensive parenting system for family interventions to strengthen the dialogue and health awareness campaign. (Sanders, 2010). In this programme, family intervention strategies should be the main feature of public health efforts to prevent family and child mental health problems. Moorhead Anne S. et al.(2013) paid attention on that, the social media is the powerful tool of social learning. The use of social media is identifying around six benefits of health communication, which includes highest interaction with others, ample of information distributions, accessibility of information resources and access to health information, instant feedback, health information surveillance and penetration of health policy in remotest areas. (Bullen \& Roberts, 2018; Sanders, 2010).

\section{Health Belief Model}

There are several psychological health behavior models but the Health Belief Model for behavior change, which is helpful to know about people"s belief on health issues and engaging all activities for health promotion among masses. Health belief model one of the oldest and famous model to establish behavior change interference (Glanz \& Bishop, 2010; Hausenblas et al., 2001; Kozel et al., 2006; Nishiuchi et al., 2016) Glanz K, Rimer BK (2005). According to the health belief model, health communication practitioners can design and develop effective strategies for health awareness. The health strategist further can utilize behavioral change communication approaches to change the attitude of the people and make them conscious about health etc.

(Nishiuchi et al., 2016). This study also purposes that a campaign should be people centric-not generalized one. A campaign should be people centric, if health practitioner expecting higher chances of achieving success in such campaigns. (Glanz \& Bishop, 2010; Kozel et al., 2006; Yoshitake, Omori, Sugawara, Akishinonomiya, \& Shimada, 2019). In this study, researchers also highlighted that proper understanding of cultural belief and social structure of the area where a strategist is supposed to launch an awareness campaign. Yoshitake, N., Omori, M., Sugawara, M., Akishinonomiya, K., \& 
Shimada, S. (2019) said that validity of Health Belief model exhibited that A structured questionnaire of TB prevention is closely monitored with health belief model and indicates several variables to study health awareness phenomenon..

\section{The Trans Theoretical Model -}

The Trans theoretical Model (TTM) - The trans-theoretical model of behavior change helpful to examine the stages of change in human nature, that why this model known as Stages of Change(Glanz\& Bishop, 2010; Hausenblas et al., 2001). This model analysis Long-term and short-term changes in health behavior like life style changes included diet, smoking habits etc. In this model, construct different sequence of behavior(Ebina et al., 2010; Galbraith-Gyan et al., 2019).

\section{- Social Cognitive Theory (SCT)}

In 1960, SCT was developed. This theory is formulation of social learning theory that has been best articulated by Bandura, explains human behavior in terms of a three-way in which personal factors, environmental influences, and behavior continually interact(Bullen \& Roberts, 2018; Stacey et al., 2015; Young, Plotnikoff, Collins, Callister, \& Morgan, 2014).

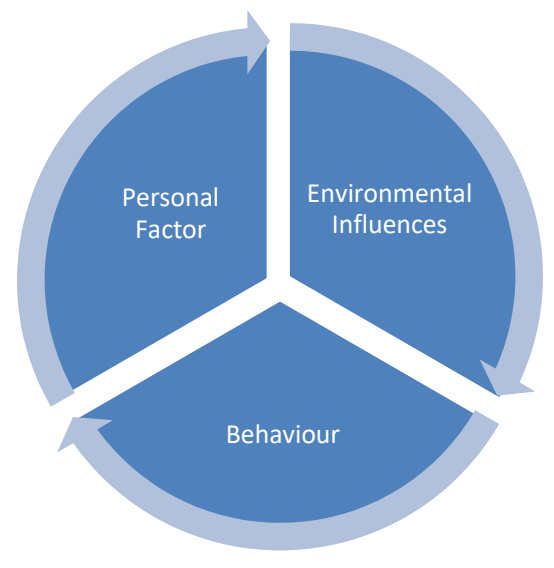

Source - Bandura, A., (1986). Social Foundations of Thought and Action: A Social Cognitive Theory. Prentice-Hall. P. 24.

Social cognitive theory is one of the most pioneer work in the field of behavior change model, which is helpful in analyzing health behavior impact and various variables. In this model, health communication focus on self- efficacy and outcome expectancies (Glanz \& Bishop, 2010). In this systematic review and meta-analysis of social learning theory researchers have concluded that social cognitive theory has potential to effect the behavior of masses positively. (Glanz \& Bishop, 2010) (Young et al., 2014) (Stacey et al., 2015).

\section{- The Theory of Planned Behavior}

The behavior scientist Icek Ajzen, described the theory of planned behavior which traces its root in the theory of reasoned action and the concept of self-efficacy(Nishiuchi et al., 2016; Rahimi, Nadri, Afshar, \& Timpka, 2018; Thoma \& Huebner, 2018). This theory incorporates major elements of the theory of reasoned action along with construction of perceived behavior. This theory also has similarity with Bandura"s concept of selfefficacy which make it unique and effective in comparison to other theories (Thoma \& Huebner, 2018)(Nishiuchi et al., 2016; Rahimi et al., 2018).

\section{Diffusion of Innovation}

In 1962, the diffusion of innovation theory was developed by Everett Mitchell Rogers. It emerged in the field of communication to explain how a new idea, practice gets spread (diffused) and became acceptable with in a community, society and population. The basic component behind adaptation is that the people think of the idea, practice, behavior and product as something new and innovation. Within the social system, the adaptation does not influence all people at once and simultaneously, some people might adopt innovation way sooner than some people while some might remain unaffected. It has been found that people with different adaptation rates to an innovation meaning adopting earlier and later have different characteristics. Mainly, there are five adopter categories that correspond to the rate of adoption in a population.

1. Innovators - People who are the first to try out the innovation. Due to their interest and willingness in new ideas, product, they have risk taking abilities and are venturesome, most likely to develop new ideas.

2. Early Adopters - People whose role is similar to the opinion leader. They being aware of the need to change usually embrace the opportunities to change and are comfortable in adopting changes. 
3. Early Majority - people who adopted new ideas, product before the average person. The typically are the ones who accept an innovation after they are witnessed the success of the innovation or believed that the idea really works.

4. Late Majority - People who tend to be skeptical of change and adopt an innovation only after it has been used by majority.

5. Laggards - People who are most slow to a new change, idea. They are bound by tradition and are very conservative. Being

very skeptical of change they are the hardest category to be persuaded to try out an innovation.

These adopter categories show the flow of adaptation of an innovation in a social system where innovators are the keenest on trying a new idea and laggards are the least interested, early adopters play the same role as the opinion leaders whereas early majority uses an innovation just before the average people of the community. Both late majority and laggards are hard to influence and try out the innovation.

\section{Research Methodology}

This research is a systematic review of health communication campaigns in previous ten years published in various scientific research journal \& databases nationally and internationally. Systematic literature review is a process to study the in-depth survey or analysis of previous conducted researches in one particular field or area of study. This gives an inside view to researcher about the various phenomenon on particular field, regarding research questions, objectives, conceptual reviews of various related theories, research techniques used and analysis withdrawn with in specific period. This helps to a researcher to find out the gaps and new dimension from where a new researcher can start his research. This Systematic Literature Review-SLR will present a very important and in-depth of past studies of health communication in India and Abroad. This review paper is directly dealing particularly with media and its role in health promotion, agenda setting for health, behavior theories etc. This study has helped the researchers to draw future line of action
Media in health awareness \& Health Communication.

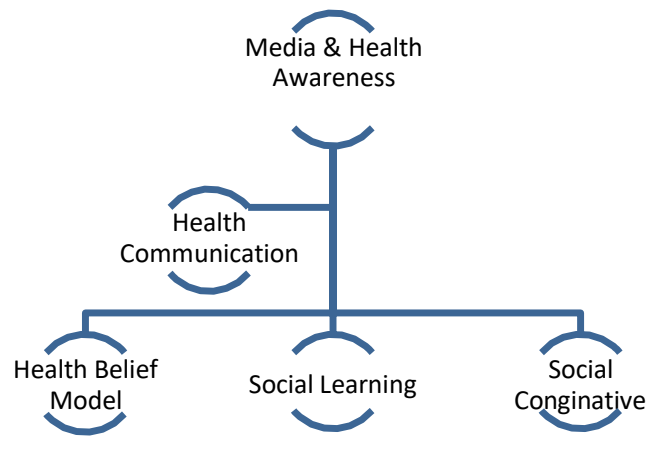

for the new researches in the field of Role of 
The research paper and articles were selected from the various journals available on Scopus \& web of science particularly open access available in India. The major portion of the selected research papers is associated with Health Communication, Health Belief Model and Social Learning etc. For the primary research and article, selection "Health Communication", "Theories of Health Communication" \& Role of Media in Health Awareness were frequently searched on these data bases to streamline the most relevant research paper on above-mentioned fields.

\section{Coding and Classification}

Lage Junior and Godinho Filho 2010, lay down the procedure of coding and classification for the systematic literature review. They advocated the several variables, indicators, and elements for the classification of systematic literature review. In this research, researchers would analysis the last ten years articles and research papers published in the field of health communication, behavior change communication, health awareness \& role of media with special emphasized on social theories of health related components. Both of the scholars suggested that category, meaning, codes of alternatives for analysis and coding. In first category researcher has analyzed the context of publication as per the developed, developing and under developed countries. In second code, researchers have indicated geographical positioning as per the continent. In third segment, objectives are studied with special emphasis on conceptual contribution, literature review, evaluation of case studies, and non-applicability. In forth code, researchers have classified the main subject of the study like agenda setting, and other theoretical framework for health communication and media with special 
emphasis on behavioral theories. In fifth code researchers have studied the concept building and methods used like qualitative, quantitative and multi method studies etc. In sixth code, researchers have evaluated the inter-relation between the theory and applicability of such theoretical models etc. In which several points were considered which are discussed thoroughly in data analysis and interpretation segment. In seventh code researchers have studied that results pertaining new knowledge, communication strategies to be modified according to the country, multiple theories effectively advocating advance people centric health policy etc. In last code researchers have concluded the period of the studies taken. For understanding, the next table will clarify the doubts related to the coding: category its meaning and codes of alternatives.

Table 1. Categories and subcategories used in this review paper.

\begin{tabular}{|c|c|c|}
\hline Category & Meaning & Codes of Alternatives \\
\hline 1 & Context & $\begin{array}{l}\text { A- Developed countries (USA+England+Austriala+Japan= } \\
\text { 17) B- Developing countries (Iran+Brazil+Ethiopia =3) } \\
\text { C- Non - applicable }\end{array}$ \\
\hline 2 & $\begin{array}{l}\text { Geographi } \\
\text { c Region }\end{array}$ & $\begin{array}{l}\text { A1 -United states of America } \\
\text { (8) B1-England (1) } \\
\text { C1-Australia (5) } \\
\text { D1-Asia (Iran -1 + Japan - 3=4) } \\
\text { E1-Africa (Brazil -1+ Ethiopia - 1= } \\
\text { 2) F1-Non- applicable }\end{array}$ \\
\hline 3 & Objectives & $\begin{array}{l}\text { A2- Conceptually contributes to } \\
\text { subject B2- Literature Review } \\
\text { C2- Present Case Study } \\
\text { D2- Non-applicable }\end{array}$ \\
\hline 4 & Main Subject & $\begin{array}{l}\text { A3-Related to Agenda Setting } \\
\text { B3- Related to multilevel health education } \\
\text { model C3- Social learning } \\
\text { D3 -Related to health belief } \\
\text { model E3-Related to } \\
\text { transtheoritical model F3 -Social } \\
\text { cognitive theory } \\
\text { G3 - Related to theory of planned behavior } \\
\text { H3 -Related to diffusion of innovation }\end{array}$ \\
\hline 5 & Method & $\begin{array}{l}\text { A4 - } \\
\text { Conceptual B4- } \\
\text { Quantitative } \\
\text { C4- Qualitative } \\
\text { D4 - Survey } \\
\text { E4 - Multi-method study }\end{array}$ \\
\hline
\end{tabular}




\begin{tabular}{|c|c|c|}
\hline 6 & Topics & $\begin{array}{l}\text { A5- Analysis link to health promotion and health } \\
\text { setting B5 -Interlink to social-cultural health. } \\
\text { C5- Analysis policy system reforms } \\
\text { D5 -Patient-provider communication and familiar } \\
\text { communication E5- Triple-P Positive parenting programs } \\
\text { F5- Parents and daughters belief about HPV infection } \\
\text { G5 -Identify suitable beliefs for selective mass communication } \\
\text { campaign. H5 - Health behavior depends on multiple factors } \\
\text { I5- To help understand, predict and explain exercise behavior } \\
\text { J5- Social cognitive theories and physical activity \& Diet } \\
\text { behavior K5- Public health and health promotion } \\
\text { L5- Parents-Adolescents communication } \\
\text { M5- Technology acceptance model in health } \\
\text { informatics N5- Community outreach programme for } \\
\text { family planning O5- Health communication } \\
\text { intervention } \\
\text { P5- Sources, awareness and preventive health behavior }\end{array}$ \\
\hline
\end{tabular}




\begin{tabular}{|l|l|l|}
\hline 7 & Results & A6- New Knowledge and Skill \\
& & B6-Communication strategies should be modified according to \\
& & country C6- Multiple theories effectively advocate for healthy \\
& public policy. \\
& & D6- New Perspectives \\
& E6 - Appropriate promotional initiatives \\
& F6- Theory based mass communication \\
& & strategies G6 - Adequate psychometric \\
& properties \\
& H6- High qualities models explained \\
& PA I6- Effective communication \\
& J6- TAM improve the performances \\
\hline 8 & Analysis & A7- Below 3 years \\
& Period & B7- Among 3 to 5 years \\
& & C7- Among 5 to 10 years \\
& D7- higher than 10 years \\
\hline
\end{tabular}

\section{Analysis and Interpretations}

are from

In this section, we are going to present the overall categorization of the articles in regards to each of the classification and coding, as shown in Table 2. Afterwards, in the sub- sections, we are going to carry out an analysis of the results we have reached through these overall classifications.

Table 2 Data classification and categorization for each paper

\begin{tabular}{|l|l|l|l|l|l|l|l|l|}
\hline S.N. & Content & Region & Objective & $\begin{array}{l}\text { Main } \\
\text { Subject }\end{array}$ & Method & Topics & Result & $\begin{array}{l}\text { Analysis } \\
\text { Period }\end{array}$ \\
\hline 1 & A & A1 & A2 & A3 & A4 & A5 & A6 & B7 \\
\hline 2 & A & B1 & A2 & A3 & B4 & B5 & B6 & A7 \\
\hline 3 & A & C1 & A2 & A3 & C4 & C5 & C6 & A7 \\
\hline 4. & A & A1 & A2 & B3 & A4 & B5 & D6 & A7 \\
\hline 5. & A & C1 & A2 & C3 & B4 & B5 & E6 & A7 \\
\hline 6. & A & A1 & A2 & C3 & A4 & D5 & D6 & A7 \\
\hline 7. & A & C1 & A2 & C3 & A4 & E5 & D6 & A7 \\
\hline 8. & A;B & A1;E1 & A2 & D3 & C4 & F5 & E6 & A7 \\
\hline 9. & A & D1 & A2 & D3 & D4 & G5 & F6 & C7 \\
\hline 10 & A & D1 & A2 & D3 & D4 & H5 & F6 & A7 \\
\hline 11 & A & A1 & A2 & E3 & A4 & I5 & G6 & A7 \\
\hline 12 & A & C1 & B2 & F3 & A4 & J5 & H6 & A7 \\
\hline 13 & A & A1 & B2 & D3;E3;F3 & A4 & K5 & F6 & A7 \\
\hline 14 & A & C1 & B2 & F3 & A4 & J5 & H6 & A7 \\
\hline 15 & A & A1 & A22 & G3 & D4 & L5 & I6 & B7 \\
\hline 16 & B & D1 & B2 & G3 & A4 & M5 & J6 & D7 \\
\hline 17 & C & E1 & C2 & H3 & D4 & N5 & I6 & A7 \\
\hline 18 & A & D1 & A2 & H3 & B4;C4 & N5 & I6 & A7 \\
\hline 19 & A;C & A1;E1 & A2 & H3 & E4 & I5 & I6 & A7 \\
\hline 20 & B & E1 & A2 & H3 & B4 & P5 & I6 & A7 \\
\hline
\end{tabular}

\section{Contextual Analysis}

First classification of this article classified in context. The context are divided into subparts $\mathrm{A}$ to $\mathrm{C}$ means $\mathrm{A}$ - developed countries, B- developing countries and C- Nonapplicable. The researchers have analyzed 20 research articles, in which $85 \%$ articles 
developed countries and rest (15\%) from developing countries. This study shows that developed countries formulate health communication strategies within framework of behavior change models and theories. Therefore, that is why health communication strategies influencing higher on developed countries in comparison to developing

countries. However, developing country framed different communication strategies without considering beliefs, cognitive behavior and attitude of masses as well as Literature review of health communication in developing countries is in crucial situation. There is scope of analyzing relationship 
between behavior change models and health theories and health communication.

- GP1 - In this article researchers have explored literature of develop countries in context of topic.

\section{Regional Analysis}

Second classification of this article relates to identification of regions. Regions are divided into different categories A1- United States of America, B1- England, C1Australia, D1- Asia (included Iran and Japan), E1-Africa (Included Brazil and Ethiopia) and F1-Non-applicable. The classification shows the diversification of research analysis. The researchers have identified the 20 research articles in which 17 articles from developed countries included USA-8, England-1, Australia - 5 and Japan - 3 included. Rest 3 articles from developing countries included Iran-1, Brazil-1 and Ethiopia - 1. This study concludes that all developed and developing countries are working on health communication within framework of behavior change theories and models.

- GP2 - There is lack of literature review on developing countries.

\section{Objective Wise Analysis}

The third category relates to objective of such articles. The objectives are coded into A2 to D2 categories in which A2conceptually contributes to subject, B2Literature review, C2- present case study and D2-non-applicable. From abovementioned 20 articles, $75 \%$ articles are related to conceptual analysis, $20 \%$ articles analyze different literature review and rest $5 \%$ relates to present case study. This study concludes that different conceptual studies of health communication are occurring specially in developed countries and there is more scope of exploring it.

- GP3 - There is lack of new terminology of Health Communication and conceptual paper of new theories and models which would be more helpful to understand conditions of Developing and under- developed countries in context of HC.

\section{Main Subject Analysis}

The fourth classification presents the main subject of research topic. The subjects are coded from A3 to H3 in which A3 - related to agenda setting, B3- related to multilevel 
education model, C3- Social learning, D3related to health belief model, E3- related to trans-theoretical model, F3 - related to social cognitive theory, G3- related to theory of planned behavior and H3related to diffusion of innovation. Under the main subjects $\mathrm{HC}$ related to different behavior change models and theories analysis included 4 paper related to diffusion of innovation, 3 paper related to agenda setting theory, social learning, health belief model, social cognitive theory as well as 2 related to planned behavior and 1 related to transtheoretical model. These all theories and models exploring relationship between HC and behavior change.

- GP4- There is a gap of theories and model spacing analysis in context of Health Communication (HC)

\section{Method Analysis}

The fifth classification explores different methods applied in analysis of articles. The method divided into A4 to E4 codes, which included A4-conceptual, B4Quantitative, C4- Qualitative, D4-Survey and E4- multi-method study. In this paper, researchers have studied

$9(45 \%)$ conceptual papers, $4 \quad(20 \%)$ survey based papers, 3 (15\%) quantitative method based papers, 2 (10\%) qualitative method based papers and $2(10 \%)$ multi-method studies are conducted. In multi-method studies included both quantitative and Qualitative methods. According to topic of research, conceptual papers are effectively analyzed different aspects of $\mathrm{HC}$ and behavior change in all situations.

- GP5- In this paper lack of qualitative and quantitative based review papers because these kind of paper promotes empirical vision as well as effective way.

\section{Topic Wise Analysis}

Sixth classification relates to different topics, which covered the articles in which included topics codes are from A5 to P5. The coding and explanation can be read as following - A5- Analysis link to health promotion and health setting, B5 Interlink to social-cultural health, C5Analysis policy system reforms, D5 Patient-provider communication and familiar communication, E5- Triple-P
Positive parenting program, F5- Parents and daughters belief about HPV infection, G5 - Identify suitable beliefs for selective mass communication campaign, H5 - Health 
behavior depends on multiple factors, I5- To help understand, predict and explain exercise behavior, J5- Social cognitive theories and physical activity \& Diet behavior, K5- Public health and health promotion, L5- Parents- Adolescents communication, M5- Technology acceptance model in health informatics, N5Community outreach programme for family planning, 05- Health communication intervention, P5- Sources, awareness and preventive health behavior. These all topics highlighted in article. The researchers have analyzed 20 papers in which $3(15 \%)$ are related to interlink to social-cultural health, $2(10 \%)$ relates to help understand, predict and explain exercise behavior and $2(10 \%)$ analysis Community outreach programme for family planning. In this, article almost all reviewed paper have own approached topics. This proved that communication and behavior change relationship can analysis through different ways.

- GP6. In these research paper, some keywords are repeatedly overlapping with each other.

\section{Application based Analysis}

The seventh classification presents results of the article, which explain through A6 to J6 code. The explanations are followings, A6- New Knowledge and Skill, B6Communication strategies should be modified according to country, C6- Multiple theories effectively advocate for healthy public policy, D6- New Perspective, E6 Appropriate promotional initiate, F6Theory based mass communication strategies, G6 - Adequate psychometric properties, H6- High qualities models explain, I6- Effective communication J6TAM improve the performances. In this study, 5 papers $(25 \%)$ have a result effective communication, 3 papers $(15 \%)$ have a result New Perspective, 3 papers (15\%) have a result Theory based mass communication strategies and 2 papers $(10 \%)$ have a result H6. This study explores different angles and aspects of HC and behavioral change. This study says that effective mass communication strategies framed with the help of different properties of behavioral change.

- GP-7 - There are different tools for effective communication but not explored in context of behavioral change communication.

\section{Analysis Period Evaluation}

In eight category, in which researchers have analyzed the articles, coded by letters A7D7 and these denote A7 - below 3 years; B7 - in between 3 and 5 years; C7- among 5 to 10 years, D7- greater than 10 years. In this paper mostly 16 papers $(80 \%)$ in the category of $A 7,2$ papers $(10 \%)$ in the category of B7, 1 paper (5\%) under the code of C7 and I paper (5\%) in the category of D7.

- GP-8 - There is the need to cover larger period of analysis. Mostly papers are in the category of less than 3 years.

\section{Conclusion and Recommendations}

The researchers have developed in this systematic literature review to establish and identify a relationship between health communication and behavior change models particularly. Researchers have analyzed effective and ineffective factors of health communication strategies for practical implications of health awareness. The researchers have explored that Health Communication based on interpersonal, group and mass communication is considerably major factors but missing in campaigns, that"s why it could not hit psychology of human beings. It is also observed that human nature, beliefs, cognitive behavior as well as attitude could change only through intrapersonal communication. This study shows that developed countries formulated health communication strategies within framework of behavior change models and theories. Therefore, health communication strategies influence effectively to developed countries society in comparison to developing countries. On the other hands, developing country framed different communication strategies without considering beliefs, cognitive behavior and attitude of masses, which results in failure of such health awareness programme.

In last, it is also noticed that that there is a gap of theories and model spacing analysis in context of Health Communication. Researchers also found while analyzing the data that there is a lack of qualitative and quantitative research, it is also observed that several tools for effective communication are yet to be explored in connection with behavioral change communication. It is pertinent to mention that the larger sample of 
the study can enhance the effectiveness of this research.

\section{References:}

- Academy, N., Society, T. R., Posetti, J., Matthews, A., Nelson, M. S., Goben, A., ... Guadagno, M. (2018). A short guide to the history of "fake news" and disinformation A LEARNING MODULE FOR JOURNALISTS AND JOURNALISM EDUCATORS. Health Communication, 162(12), 412-424. https://doi.org/10.

1016/j.ahj.2011.06.007.Medication

- Bang, K. S., Chae, S. M., Lee, I., Yu, J., \& Kim, J. (2018). Effects of a Community Outreach Program for Maternal Health and Family Planning in Tigray, Ethiopia. Asian Nursing Research, 12(3), 223-230. https://doi.org/10.1016/j.anr.2018.0 8.007

- Bullen, J., \& Roberts, L. (2018). From the outside in: tutor perspectives of student transformative experiences within Indigenous Studies health education. Higher Education Research and Development, $o(0)$, 1-15.

https://doi.org/10.1080/ 07294360.2018 .1549538

- Ebina, R., Kawasaki, F., Taniguchi, I., Togari, T., Yamazaki, Y., \& Sparks, M. (2010). The effectiveness of health communication strategies in health education in Kushima, Japan. Global Health Promotion, 17(1), 5-15. https://doi.org/10. $1177 / 1757975909356628$

- Galbraith-Gyan, K. V., Lechuga, J., Jenerette, C. M., Palmer, M. H., Moore, A. D., \& Hamilton, J. B. (2019). AfricanAmerican parents" and daughters" beliefs about HPV infection and the HPV vaccine. Public Health Nursing, 36(2), 134-143. https://doi.org/10.1111/phn.12565

- Glanz, K., \& Bishop, D. B. (2010). The Role of Behavioral Science Theory in Development and Implementation of Public Health Interventions. Annual Review of Public Health, 31(1), 399-418. https://doi.org/10.1146/annurev.p ublhea lth.012809.103604

- Harris, P., Kent, J., Sainsbury, P., MarieThow, A., Baum, F., Friel, S., \& McCue, P. (2018). Creating „healthy built environment" legislation in Australia; A 
International, $\quad 33(6), \quad$ 1090-

1100.

https://doi.org/10.1093/heapro/ dax 055

- Hausenblas, H. A., Nigg, C. R., Dannecker, E. A., Downs, D. S., Gardner, R. E., Fallon, E. A., ... Loving, M. G. (2001). A missing piece of the transtheoretical model applied to exercise: Development and validation of the temptation to not exercise scale. Psychology and Health, 16(4), 381-390. https://doi.org/10.1080/08870440 108405514

- $\quad$ Kozel, C. T., Kane2, W. M., Hatcher3, M. T., Hubbell, A. P., Dearing, J. W., Forster- Cox, S., Goodman, M. (2006). Introducing Health Promotion Agenda- Setting for Health Education Practitioners. Californian Journal of Health Promotion, 4(1), 32-40.

Retrieved from http://www.cjhp.org/Volume4_20 06/Iss ue1/32-40-kozel.pdf

- Llamas, A., \& Mayhew, S. (2016). The emergence of the vertical birth in Ecuador: An analysis of agenda setting and policy windows for intercultural health. Health Policy and Planning, 31(6), 683-690. https://doi.org/10.1093/heapol/ czv118

- McBride, C. M., Birmingham, W. C., \& Kinney, A. Y. (2015). Health Psychology and Translational

Genomic Research...Cancer and Psychology special issue. American Psychologist, 70(2), 91-104 14p. https://doi.org/10.1037/a0036568

- $\quad$ Mertens, F., Távora, R., Nakano, E. Y., \& Castilhos, Z. C. (2017). Information sources, awareness and preventive health behaviors in a population at risk of Arsenic exposure: The role of gender and social networks. PLOS ONE, 12(10), $1-14$ https://doi.org/10.1371/journal.p one.018 6130

- $\quad$ Nishiuchi, H., Taguri, M., \& Ishikawa, Y. (2016). Using a marginal structural model to design a theory-based mass media campaign. PLOS ONE, 11(7), 112. https://doi.org/10.1371/journal.po ne.015 8328

- Rahimi, B., Nadri, H., Afshar, H. L., \& Timpka, T. (2018). A systematic review of the technology acceptance model in health informatics. Applied Clinical Informatics, 9(3), 604-634. https://doi.org/10.1055/s- 00381668091 
- Sanders, M. R. (2010). Triple P - Positive Parenting Program: A population approach to promoting competent parenting. Australian E-Journal for the Advancement of Mental Health, 2(3), 127143. https://doi.org/10.5172/jamh.2.3.12 7

- Scheirer, M. A., Santos, S. L. Z., Tagai, E. K., Bowie, J., Slade, J., Carter, R., \& Holt,

C. L. (2017). Dimensions of sustainability for a health communication intervention in African American churches: A multi- methods study. Implementation Science, 12(1), 1-12. https://doi.org/10.1186/ s13012-017-0576-x

- Stacey, F. G., James, E. L., Chapman, K., Courneya, K. S., \& Lubans, D. R. (2015). A systematic review and meta-analysis of social cognitive theory-based physical activity and/or nutrition behavior change interventions for cancer survivors. Journal of Cancer Survivorship, 9(2), 305-338.https:

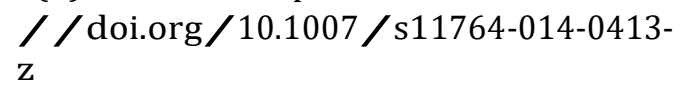

- Starmann, E., Heise, L., Kyegombe, N., Devries, K., Abramsky, T., Michau, L., ... Collumbien, M. (2018). Examining diffusion to understand the how of SASA!, a violence against women and HIV prevention intervention in Uganda. BMC Public Health, 18(1), 1-20. https:// doi.org/10.1186/s12889-018-5508-4
- Thoma, B. C., \& Huebner, D. M. (2018). Parent-adolescent communication about sex and condom use among young men who have sex with men: An examination of the theory of planned behavior. Annals of Behavioral Medicine, 52(11),

973-987. https://doi.org/10.1093/abm/kay0 02

- Williams, O., \& Swierad, E. M. (2019). A Multisensory Multilevel Health Education Model for Diverse Communities. International Journal of Environmental Research and Public Health, 16(5). https://doi.org/10.3390/ijerph1605 0872

- Yoshitake, N., Omori, M., Sugawara, M., Akishinonomiya, K., \& Shimada, S. (2019). Do health beliefs, personality traits, and interpersonal concerns predict TB prevention behavior among Japanese adults? PLOS ONE, 14(2), 1-10. https://doi.org/10.1371/journal.po ne.021 1728

- Young, M. D., Plotnikoff, R. C., Collins, C. E., Callister, R., \& Morgan, P. J. (2014). Social cognitive theory and physical activity: A systematic review and metaanalysis. Obesity Reviews, 15(12), 983995.

https://doi.org/10.1111/obr.12225 